\title{
COMBINATION OF REGENERATIVE PROCEDURE AND ENDODONTIC TREATMENT IN ENDO-PERIO LESION: A CASE REPORT
}

\section{WILSON $^{1}$, ARMIA SYAHPUTRA ${ }^{2}$, DWI PUSPARANI ${ }^{3} \&$ TRIMURNI ABIDIN $^{4}$}

${ }^{1}$ Periodontics Residency Program, Faculty of Dentistry, Universitas Sumatera Utara, Medan, Indonesia

${ }^{2}$ Department of Periodontics, Faculty of Dentistry, Universitas Sumatera Utara, Medan, Indonesia

${ }^{3}$ Conservative Dentistry Residency Program, Faculty of Dentistry, Universitas Sumatera Utara,

Medan, Indonesia

${ }^{4}$ Department of Conservative Dentistry, Faculty of Dentistry, Universitas Sumatera Utara, Medan, Indonesia

\begin{abstract}
Introduction: The relationship between the periodontal and endodontic lesion disease was first described by Simring and Goldberg in 1964 which referred to it as an "endo-perio lesion". The success of the treatment is depending on the proper identification of the causes. The treatment might require both endodontic therapies combine with a periodontal regenerative procedure. The present case report shows a combination of endodontic treatment with a GTR procedure.

Case Report: A 21 years old man came to periodontics department, University of Sumatera Utara with a chief complaint of tooth mobility in a lower lateral incisor with a gingival enlargement. Intra oral examination shows grade II mobility with an interdentally gingival inflammation and a trauma from occlusion on tooth 42 and clinical examination shows a non-vital tooth with a infrabony pocket. A combination of endodontic treatment and GTR procedure was performed in this case.

Discussion: Determination the main causes in endo-perio lesion plays an important role which affected the treatment plan of the case. Proper history taking and sequential treatment planning are important for a successful treatment of this lesion. Combination of guided tissue regeneration (GTR) with an adequate root canal treatment in the involvement of pulpal and periodontal lesion will increase the prognosis of a tooth.

Conclusion: Endo-perio lesion presents a challenge in diagnostic and treatment plan. Through proper identification and good treatment plan such as root canal treatment combine with a GTR procedure, it shows a good and predictable outcome.
\end{abstract}

KEYWORDS: Endo-Perio Lesion, Bone Graft, Guided Tissue Regeneration

Received: Jun 01, 2020; Accepted: Jun 20, 2020; Published: Jun 29, 2020; Paper Id.: IJMPERDJUN2020122

\section{INTRODUCTION}

The endodontium and periodontium are closely related to each other and the involvement of this disease might be a two way which we often called as "endo-perio" lesion. This endo-perio lesion happened in the same tooth which make it difficult to diagnose and to treat. The pathway for spread of disease bacteria between periodontal and pulpal had been discuss in many literatures. ${ }^{1}$

The most common used classification of endo-perio lesion was by Simon et al in 1972 which divided this classification into a few categories: 1. Primary endodontic lesion 2. Primary endodontic lesion with secondary periodontal involvement, 3. Primary periodontal lesion, 4. Primary periodontal lesion with secondary endodontic 
involvement 5. True combined lesions. ${ }^{2}$ the newest classification was described by the European Federation of Periodontology (EFP) in 2017 which divided this categorized into two big categories which is endo-periodontal lesion with root damage or endo-periodontal lesion without root damage. ${ }^{3}$

Treatment of endo-periodontal lesion are depending on the primary cause on the lesion. The treatment might require both endodontic therapies combine with a periodontal regenerative procedure. This article presents a case report of and endoperiodontal lesion without root damage in a lower lateral incisor with a combination of endodontic therapy and periodontal regenerative procedure .

\subsection{Case Report}

A 21 years old man came to periodontics department, Universitas Sumatera Utara with a chief complaint of tooth mobility in a lower lateral incisor with a gingival enlargement. Patient was systemically healthy and non-contributory medical history. Intra oral examination shows a grade II mobility with an interdentally gingiva inflammation and a trauma from occlusion on tooth 42 [Fig 1a, b]. Patient had a good oral hygiene and probing pocket depth of $12 \mathrm{~mm}$ and $10 \mathrm{~mm}$ was recorded respectively on the distal labial and lingual aspect on tooth 42 . No carious lesion was found on the tooth however the tooth had a negative response toward thermal and electric pulp test. Intra-oral periapical radiograph (IOPR) shows a wide vertical bony defect and widening of periodontal ligament (Figure 1c).

On the first appointment full mouth scaling root planning was done followed by a provisional splinting, occlusal reduction and root canal treatment. Re-evaluation of patient after 14 days shows a decrease of interdental gingival enlargement and a probing depth shows a decrease of pocket to $9 \mathrm{~mm}$ and $7 \mathrm{~mm}$ respectively recorded on the distal labial and lingual aspect. Patient was recalled 3 months after the root canal treatment and IOPR shows a persistent of vertical bone defect with a no changes of probing depth [Figure 2a-c]. Therefore, periodontal regenerative surgery was planned for treatment of vertical defect.
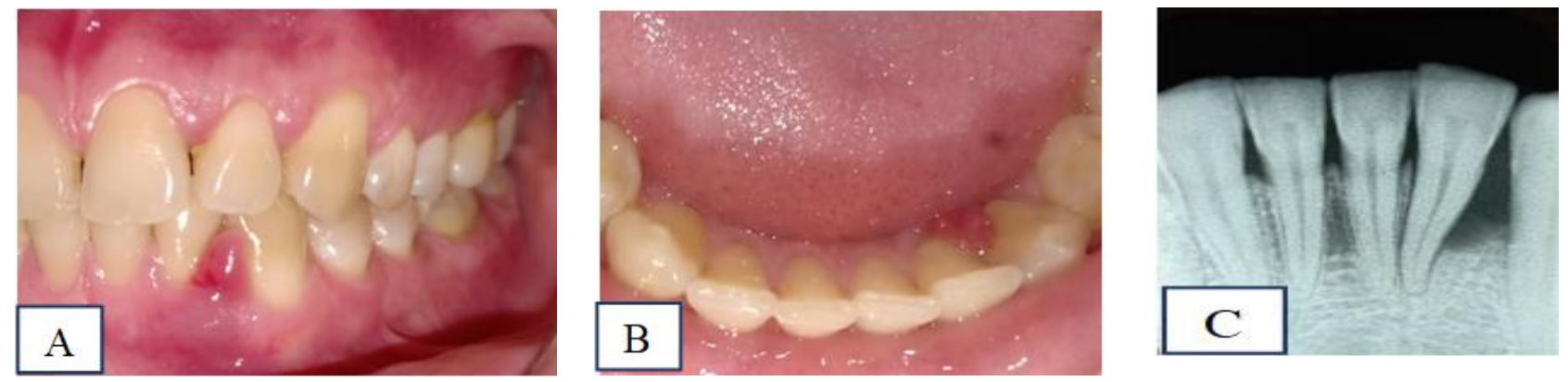

Figure 1: A) Initial View of Tooth 42 on Labial Aspect, B) Lingual Aspect \& C) Initial IOPR of Tooth 42.
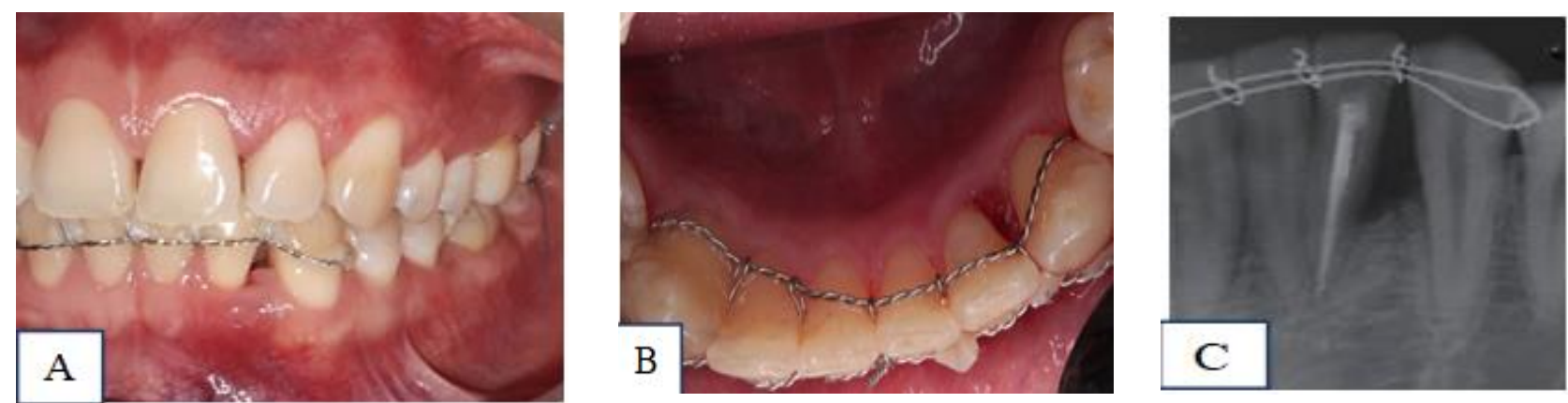

Figure 2: 3-Month Re-Evaluation of Tooth 42 A) Labial Aspect, B) Lingual Aspect, C) Persistent Vertical Defect Was Seen 


\subsection{Regenerative Periodontal Therapy Procedure}

Before the surgery patient was given an aseptic procedure extra and intraoral with a $2 \%$ povidone-iodine. The procedure was carried out under local anesthesia (articaine $4 \%$ with epinephrine 1: 100,000). A horizontal incision was given $2 \mathrm{~mm}$ below the interdental of the mesial and distal aspect of tooth 42 with a purpose to preserve the intact of interdental papilla. A vertical incision was given on the distal of tooth 41 and 43 and a sulcular incision was done from tooth 41 to 43 . A fullthickness flap was raised with a combination of periosteal releasing incision to create a free-tension flap [Fig 3a, b]. Granulation tissue was removed using a Gracey curretes and root planning procedure was done. A 2-wall bone defect was seen and a xenograft bone graft material was placed into the defect follow by a placement of pericardium membrane [Fig 4a-c]. The flap was suture with 5-0 blue nylon tightly to the interdental papilla [Fig 5] and post-operatively care treatment was given to the patient.
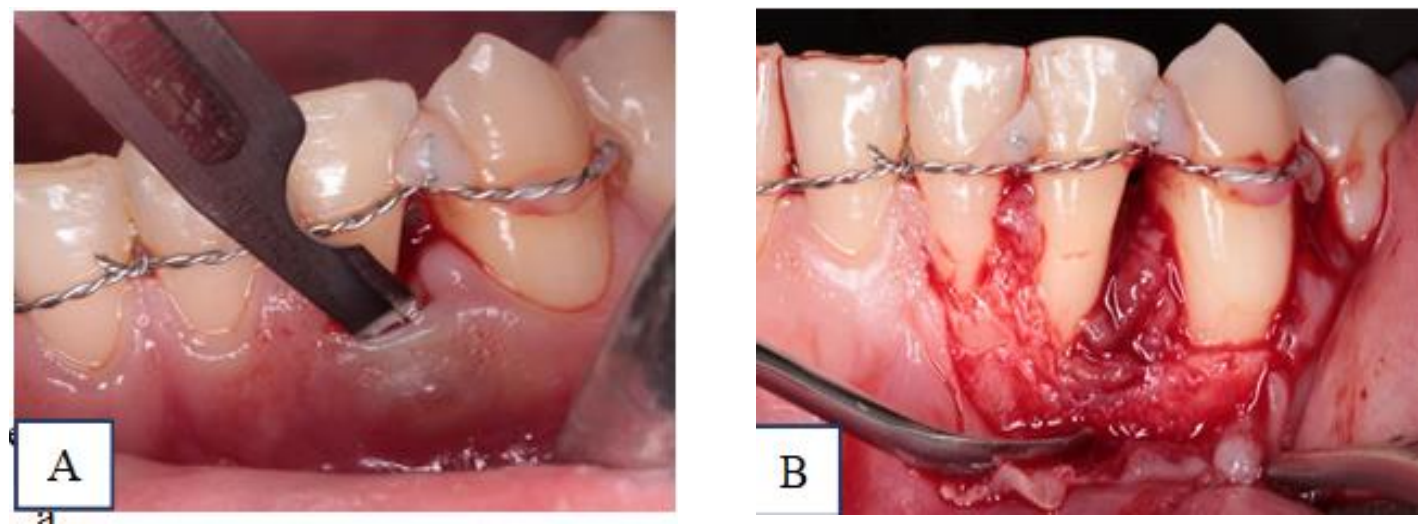

Figure 3: A) Sulcular Incision on Tooth 42, B) Full Thickness Flap was Raised.
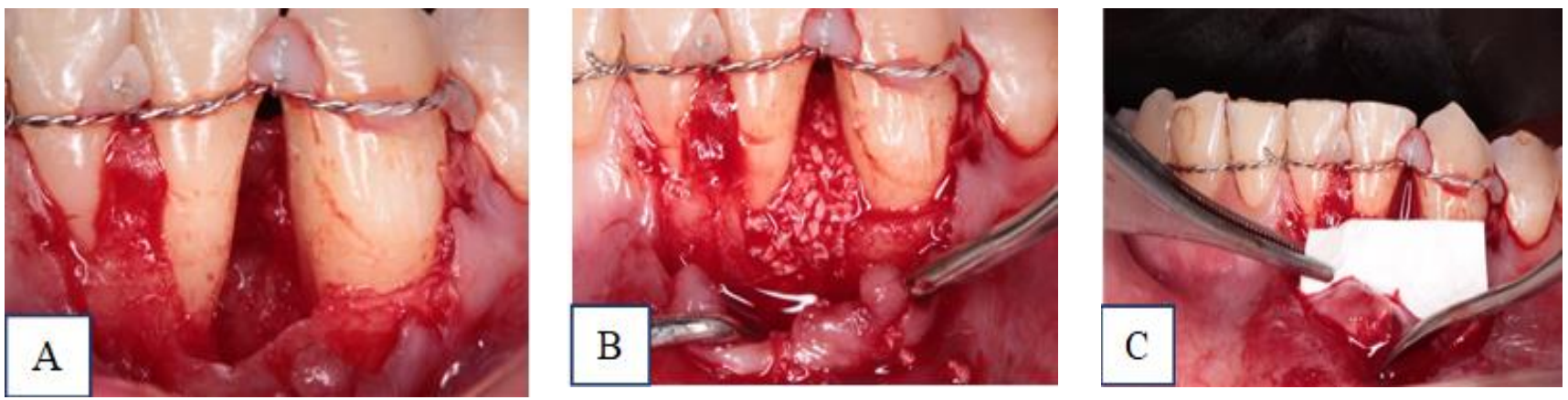

Figure 4. A) 2-Wall Defect Was Seen on Tooth 42, B) Xenograft Placement \& C. Membrane Placement.

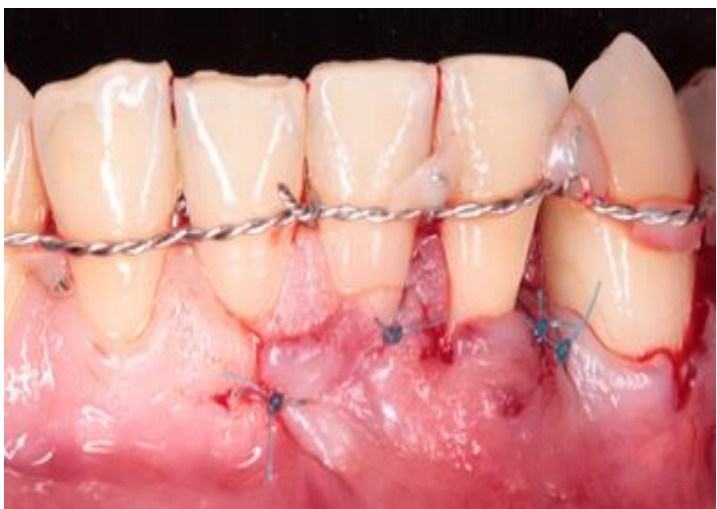

Figure 5. Interrupted Sutured Was Performed. 


\subsection{Post-Operative Care}

The patient was instructed not to disturb the surgical site in any way until the sutures were removed. Other post-operative instructions were also given. The patient was advised to take antibiotics \& analgesics for 7 days postoperatively (Amoxicillin 500mg \& Mefenamic Acid 500mg). Use of $0.12 \%$ chlorhexidine rinse was also advised. Two weeks postoperatively the sutures were removed. Healing was satisfactory and a no sensitive pain was reported [Fig 6 a, b]. The patient was recall regularly. After 4 month the probing depth shows a reduced by $2 \mathrm{~mm}$ and clinical examination shows a growth of interdental papilla both on the labial and lingual aspect with a stable bone graft [Fig 7 a-c].
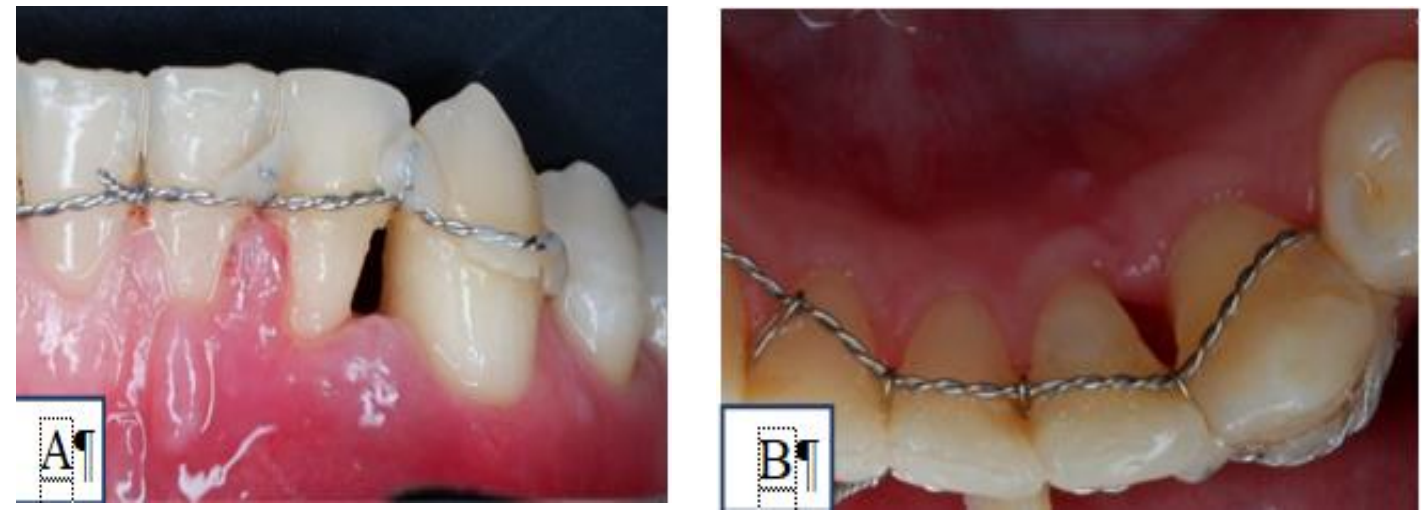

Figure 6: Clinical View of 2 Weeks Post-Operatively A) Labial Aspect,

B) Lingual Aspect.
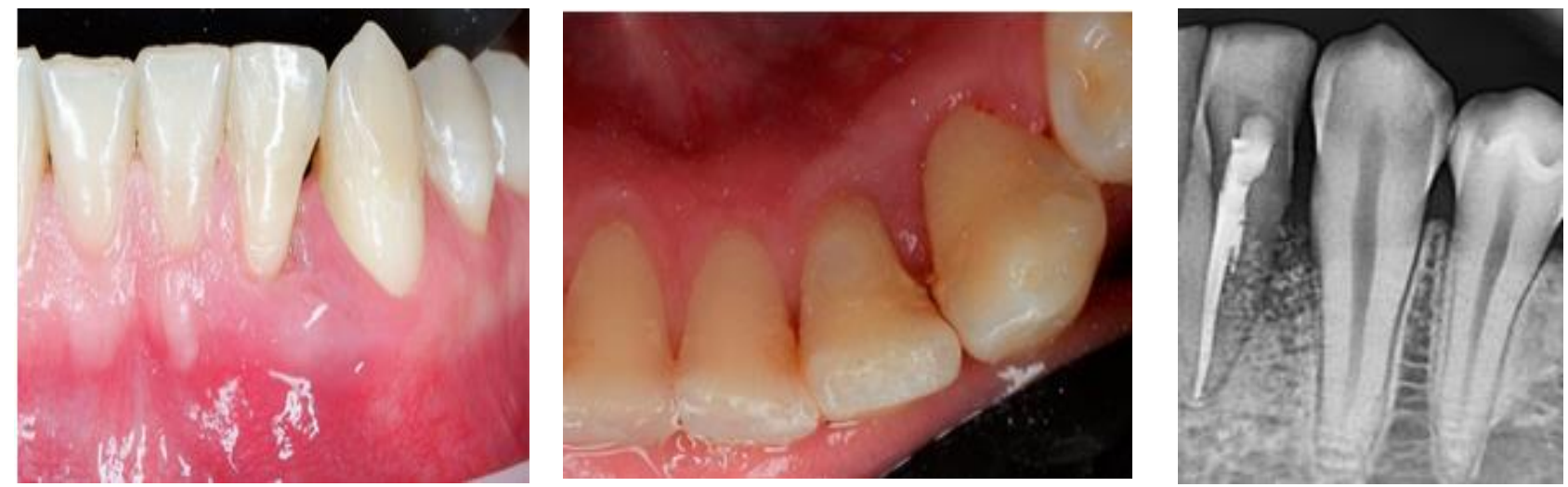

Figure 7: Clinical View and Radiography at the 4 Months Recall A) Labial Aspect, B) Lingual Aspect, C) A Stable Bone Graft Was Shown in the IOPR.

\section{DISCUSSIONS}

Treatment of endo-perio lesion have always been a challenge for the dentist. Endo-perio lesion is a clinical manifestation of inflammatory intercommunication between the periodontal tissue and pulpal via structures such as dentinal tubules, lateral or accessory canals and apical foramen. ${ }^{4}$ Determination the main causes in endo-perio lesion plays an important role which affected the treatment plan of the case. Proper history taking and sequential treatment planning are important for a successful treatment of this lesion. ${ }^{5}$

In the present case, no carious lesion was found on tooth 42 but a deep periodontal pocket with a non-vital examination test was found. Radiographic examination showed an advanced of periodontal bone loss until apical one third. Through this finding according to the Simons classification we concluded that it was a primary periodontal lesion with 
secondary endodontic involvement and according to the EFP classification this case was diagnose as endo-periodontal lesion without root damage. Study by Adriaens et al showed that dentinal tubules was a reservoir for microorganism to infected tooth. ${ }^{6}$ Rubach and Mitchell suggested that accessory canals had a possible role as a pathway of periodontal lesion with a secondary endodontic involvement. ${ }^{7}$

Combination of guided tissue regeneration (GTR) with an adequate root canal treatment in the involvement of pulpal and periodontal lesion will increase the prognosis of a tooth. GTR procedure is a procedure which involve a removal of granulation tissue and a placement of bone graft with a purpose of creating a healthy periodontal tissue ${ }^{8,9,10}$ Xenograft bone graft was used in this cased because it has a osteoconductive properties and act as a scaffold for the growth and deposition of new bone formation. A non-resorbable membrane was used a barrier toward the epithelial cells and no second surgical intervention should be performed.

The result of this case shows a satisfied result of the regenerative procedures which shown by the increasing of papilla interdental and a significant amount of bone fill with a reduction of pocket depth.

\section{CONCLUSIONS}

Endo-perio lesion presents a challenge in diagnostic and treatment plan. Through proper identification and good treatment plan such as root canal treatment combine with a GTR procedure, it shows a good and predictable outcome.

\section{ACKNOWLEDGEMENT}

The authors would like to thank the Faculty of Dentistry, Universitas Sumatera Utara

\section{REFERENCES}

1. Nanavati B, Bhavsar NV, Mali J. Endo Periodontal Lesion-A Case Report. JOAOR. 2013; 4(3): 1720.

2. Daing A, Arora V. Management of Periodontal-Endodontic Lesion by Regenerative Approach: A Case Report. IOSR-JDMS. 2016; 15(12): 1114 .

3. Caton JG, Armitage G, Berglundh T, Chapple ILC, Jepsen S. Kornman KS et al. Systemic and Other Periodontal Condition. J Clin Periodontol. 2018; 45(Suppl 20):518.

4. Kambale S, Aspalli N, Munavalli A, Ajgaonkar N, Babannavar R. A Sequential Approach in Treatment of Endo-Perio Lesion A Case Report. JCDR. 2014; 8(8): 224.

5. Agarwal R, Singh V, Kambalyal P, Jain K. Management of Endo-Perio Lesion with Regenerative Procedure- A Case Report. Int J Oral Health Med Res. 106; 3(1): 11921.

6. Adriaens PA, Edwards CA, de Boever JA, and Loesche WJ.Ultrastructural observations on bacterial invasion in cementum and radicular dentin of periodontally diseased human teeth J Periodontol 1988; 59:493503.

7. Rubach WC and Mitchell DF “Periodontal disease, accessory canals and pulp pathosis, " J Pertiodontol 1965; $36: 3438$.

8. Alquthami H, Almalik AM, Alzahrani FF, Badawi L. Succeful Management of Teeth with Different Types of EndodonticPeriodontal Lesions. CRD 2018. 17.

9. Reddy AK, Reddy NS, Kumar PM, Rao SP. Treatment of Endo-Perio Lesion with Syringable Bio Active Alloplastic Bone Graft Material: A Case Report. AEDJ. 2012;4(1).5962.

10. Sheikh Z, Hamdan N, Ikeda Y, Grynpas M, Ganss B, Glogauer M. Natural Graft Tissues and Synthetic Biomaterials for 
Periodontal and Alveolar Bone Reconstructive Applications: A Review. Biomaterials Research. 2017; 21(9):120.

11. Shukla, Sagrika, Vidhi Gupta, and Ashi Chug. "One Year Follow Up of an Iatrogenic Root Perforation Treated With Mineral Trioxide Aggergate (MTA) and Vertical Bone Loss Grafted with Novabone Bone Graft Plus Platelet Rich Plasma (PRP)." International Journal of Dental Research \& Development (IJDRD) 6.2 (2016): 112.

12. MAHESH, LANKA, et al. "IMMEDIATE IMPLANT PLACEMENT IN POSTERIOR MAXILLA." International Journal of Dental Research \& Development (IJDRD) 8.1 (2018):14.

13. BHAGWAT, SHREYAS V., VISHAL V. SHUKLA, and MOHAN G. TRIVEDI. "AN ENGINEERING INVESTIGATION OF BIOPOLYMERS." International Journal of Mechanical and Production Engineering Research and Development (IJMPERD) 9 , Special Issue (2019):348355.

14. SHANKAR, UMA, et al. "ORTHOMORPHIC SURGERY FOR MANDIBULAR DEFORMITY-A CASE SCENARIO." International Journal of Dental Research \& Development (IJDRD) 9.2 (2019):110.

15. LOHAKARE, SANDHYA SHYAM. "FAST MOVEMENT OF TEETH DURING ORTHODONTIC TREATMENT." International Journal of Dental Research \& Development (IJDRD) 4.6 (2014):714.

16. Bajwa, M. О. Н. А. М. М. A. D. "Nanomedicine-The Futuristic Medicine." International Journal of General Medicine and Pharmacy (IJGMP) 6.1 (2017): 18. 